\author{
$3^{\text {rd }}$ year final contractor report for: \\ U.S. Department of Energy \\ Stewardship Science Academic Alliances Program
}

Sponsor ID \#: DE-FG03-02NA00060

TEES (Texas A\&M) Project\#: 69390/32525

\title{
Project Title: \\ Detailed Measurements of Rayleigh-Taylor Mixing at Large and Small Atwood Numbers
}

Report date:

Project starting date:

Principle Investigator:
April 14, 2006

September 14, 2002

Professor Malcolm J. Andrews

Department of Mechanical Engineering

Texas A\&M University, College Station, TX 77845

Tel: (979) 8478843

e-mail: mandrews@tamu.edu

\begin{abstract}
This project had two major tasks:

Task 1.The construction of a new air/helium facility to collect detailed measurements of Rayleigh-Taylor (RT) mixing at high Atwood number, and the distribution of these data to LLNL, LANL, and Alliance members for code validation and design purposes.

Task 2.The collection of initial condition data from the new Air/Helium facility, for use with validation of RT simulation codes at LLNL and LANL.

This report describes work done in the last twelve (12) months of the project, and also contains a summary of the complete work done over the three (3) life of the project. As of April 1, 2006, the air/helium facility (Task 1) is now complete and extensive testing and validation of diagnostics has been performed. Initial condition studies (Task 2) is also complete.

Detailed experiments with air/helium with Atwood numbers up to 0.1 have been completed, and Atwood numbers of 0.25. Within the last three (3) months we have been able to successfully run the facility at Atwood numbers of 0.5 . The progress matches the project plan, as does the budget. We have finished the initial condition studies using the water channel, and this work has been accepted for publication on the Journal of Fluid Mechanics (the top fluid mechanics journal). Mr. Nick Mueschke and Mr. Wayne Kraft are continuing with their studies to obtain PhDs in the same field, and will also continue their collaboration visits to LANL and LLNL. Over its three (3) year life the project has supported two(2) Ph.D.'s and three (3) MSc's, and produced nine (9) international journal publications, twenty four (24) conference publications, and numerous other reports. The highlight of the project has been our close collaboration with LLNL (Dr. Oleg Schilling) and LANL (Drs. Dimonte, Ristorcelli, Gore, and Harlow).
\end{abstract}




\section{Contents}

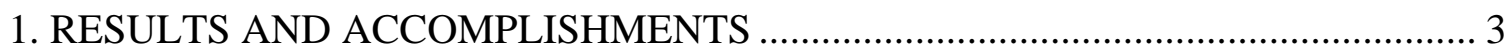

1.1 Introduction..................................................................................................... 3

1.2 Task 1: Construction of the new Air/Helium RT Mix Facility............................... 3

1.3 Task 2: Collection of Initial Condition Data......................................................... 6

2. CURRENT AND FUTURE WORK .................................................................... 7

3. PARTICIPANTS AT TAMU DURING THE $3^{\text {rd }}$ YEAR........................................ 8

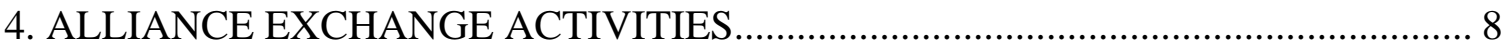

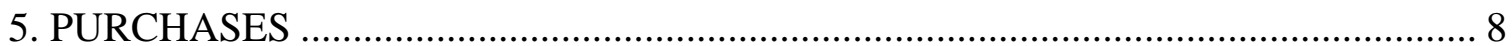

6. PUBLICATIONS AND PRESENTATIONS REFERENCING PROJECT (copies

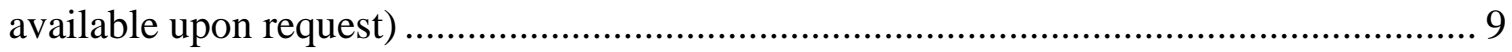

6.1 Journal Publications Since $2^{\text {nd }}$ Year Report........................................................ 9

6.2 Conference Presentations Since $2^{\text {nd }}$ Year Report.................................................. 9

6.3 Other Presentations Since $2^{\text {nd }}$ Year Report ....................................................... 10

6.4 Other Publications Since $2^{\text {nd }}$ Year Report ......................................................... 11

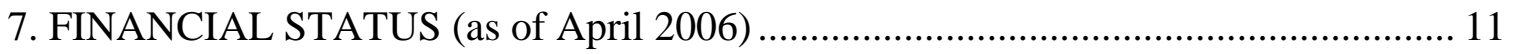

APPENDIX A: Summary of Project Journal and Conference Publications..................... 12

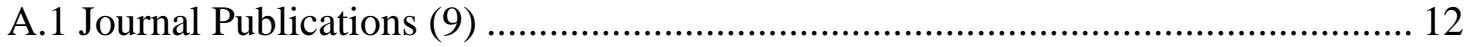

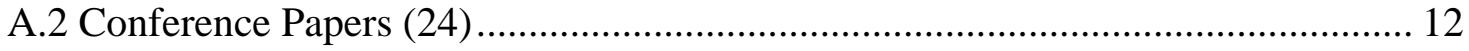




\section{RESULTS AND ACCOMPLISHMENTS}

\subsection{Introduction}

The project involved collecting statistical turbulence data from a new high Atwood (At) number (a non-dimensional measure of density ratio) Rayleigh-Taylor (RT) mixing facility that has been built as part of the project. The experiment investigated buoyancy driven RT mixing that is relevant to ICF implosion. The data has been, and will continue to be, provided to Alliance members (specifically LLNL and LANL) for code validation and turbulence model formulation/testing. The experiment is a natural follow-on from our small Atwood number (water channel) facility that has been in use for almost thirteen (13) years. The new facility has now been built and uses air and helium to achieve Atwood numbers up to 0.75. Since mixing of air and helium is involved the fluids are miscible with Prandtl and Schmidt numbers close to one. The new air/helium facility is similar to the water channel whose details may be found in the papers associated with the present work, referenced in section 6 below, and available upon request.

A detailed account of all the successes associated with this project would make this report far to extensive (several of the publications are in excess of 40 journal pages). Consequently please do not hesitate to contact the PI for copies of the publications, or for a detailed discussion of this research.

The organization of this final year report is to present a description of the accomplishments and results, and in particular progress and results from the new air/helium gas channel, and initial condition studies performed with the water channel. The report closes with an account of alliance activities, purchases, publications and presentations from the project, financial status, and an appendix with a complete list of archival publications that includes nine (9) international journal publications (3 of which were in the prestigious Journal of Fluid Mechanics), and over twenty (20) conference publications.

\subsection{Task 1: Construction of the new Air/Helium RT Mix Facility}

This task spanned the first and second years of the project, and is associated with the construction and shakedown of the new air/helium facility.

Figure 1 (over the page) shows a schematic of the air/helium facility taken from the original proposal. Figure 2 shows a photograph of the new air/helium facility, with Mr. Michael Peart (undergraduate Research Assistant) as a reference scale. Inspection of Figure 2 shows that construction of the facility is complete and corresponds to the schematic design. However, one significant improvement was made, the depth of the flow channel was increased from $60 \mathrm{~cm}$ to $120 \mathrm{~cm}$ (4ft), the width from $40 \mathrm{~cm}$ to $60 \mathrm{~cm}$ (2ft), and the length from $3 \mathrm{~m}$ to $6 \mathrm{~m}$ (19ft). This change was done to increase the operational Reynolds number by a factor of two (2), so it could reach 20,000, with a nominal increase in cost, and no need for additional funds. The flow channel dominates the center of the photograph, and may be divided into four parts going from right to left; 
the entrance duct work that feeds air on top and helium below (the helium bottles are behind the flow channel and not visible in the photograph); the splitter plate that starts with the honeycomb flow straightener and continues with wire meshes to control boundary layer development; after the splitter comes the main flow channel where buoyancy driven mixing takes place; and lastly, the exit plenum that vents to the outside. Below the flow channel can be seen air intakes for fans that feed the channel.

To illustrate a typical experiment Figure 3 shows an experimental photograph taken using smoke as a marker for the light fluid (on the bottom). Figure 3 is used to obtain mean density profiles and mix widths as the RT mix develops. The Hot Wire diagnostic is used to obtain velocity and density fluctuation statistics. An extensive set of data may be found in reference 6.1.6 given in section 6 below.

Our work to run at high Atwood numbers $(\sim 0.5)$ over the last year resulted in a problem with "back-flow" from the entrance plenum. The back-flow effect was heavy fluid (air) falling down to the bottom of the channel and then flowing backwards toward the inlet. This back-flow phenomena had been previously seen in the water channel and was resolved by running the channel at higher velocities, and "bleeding" the heavy fluid from the exit plenum. After some experimentation neither of these methods was found satisfactory. Instead an exit plenum splitter plate was installed that effectively prevented the heavy fluid (air) from falling into the exit plenum, and thus preventing the back-flow. Since the flow itself is parabolic the exit plenum splitter did not affect the upstream mixing, and solved the back-flow problem up to the maximum Atwood number of the experiment $\sim 0.75$. This is an important development as it has made the facility reliable up to high Atwood numbers, and perhaps suggests a solution to back-flow problems that would prevent the facility being used for At $>0.75$ in potential future experiments.

\section{Side View}

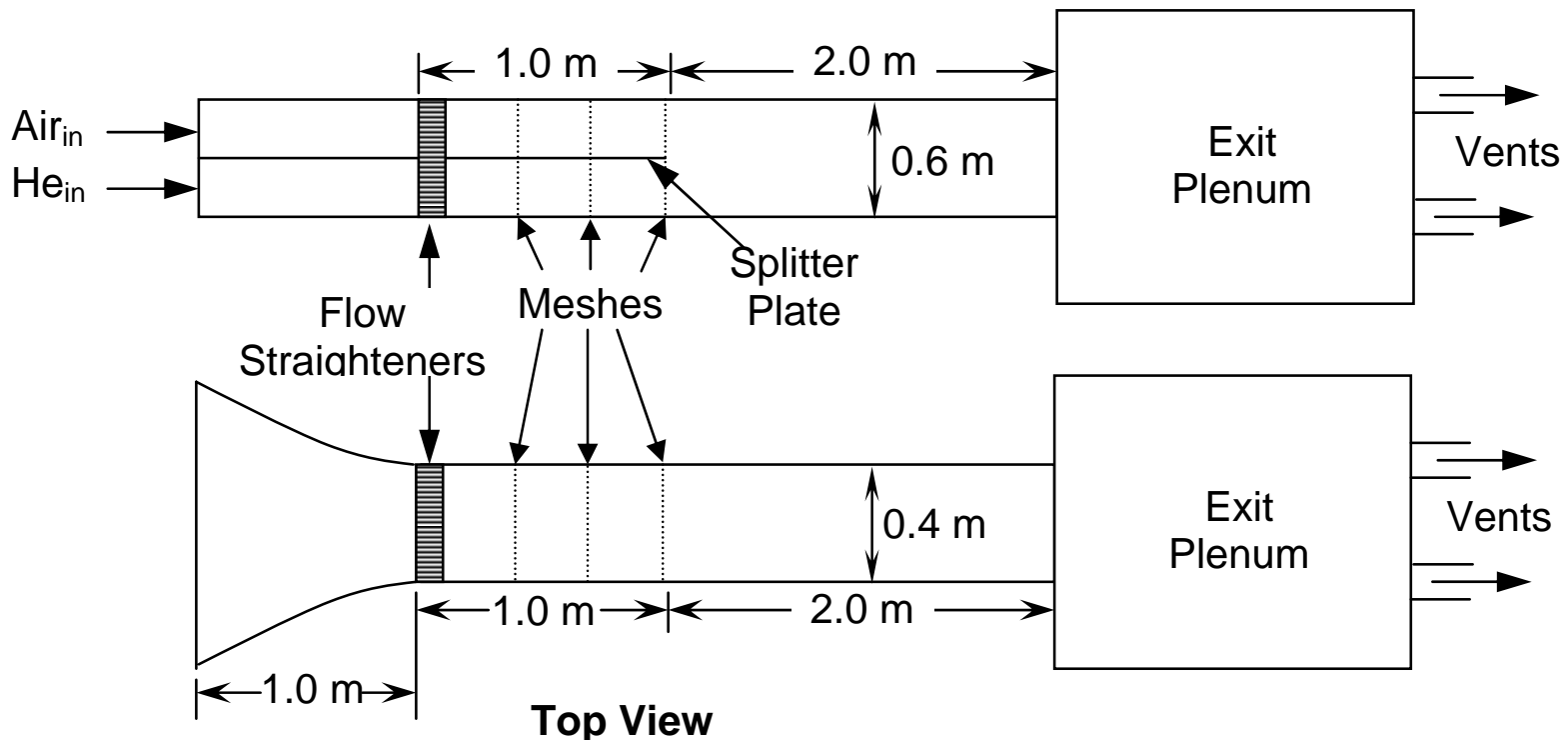

Figure 1. Schematic of the Air/Helium Facility taken from the Proposal 


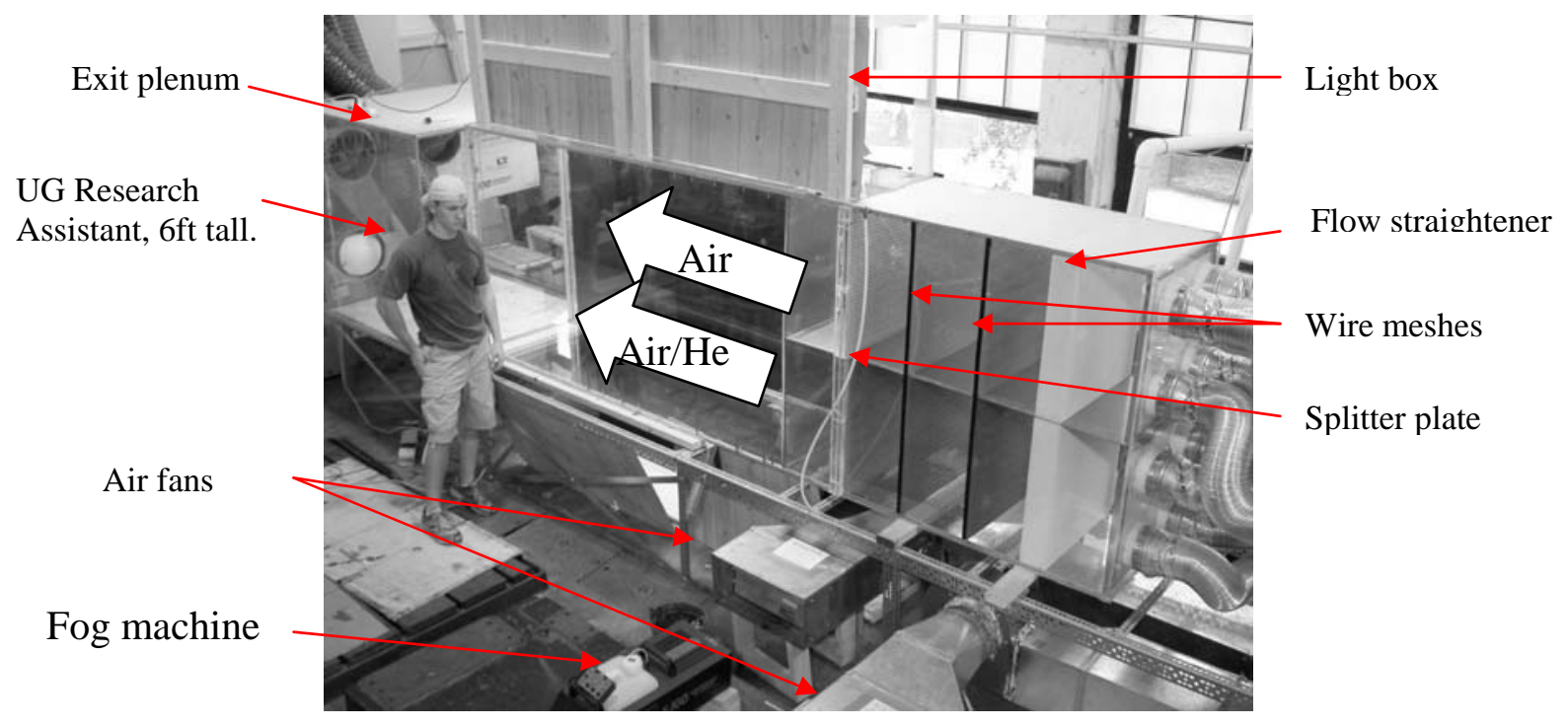

Figure 2. Photograph of Gas Channel, August 2004.

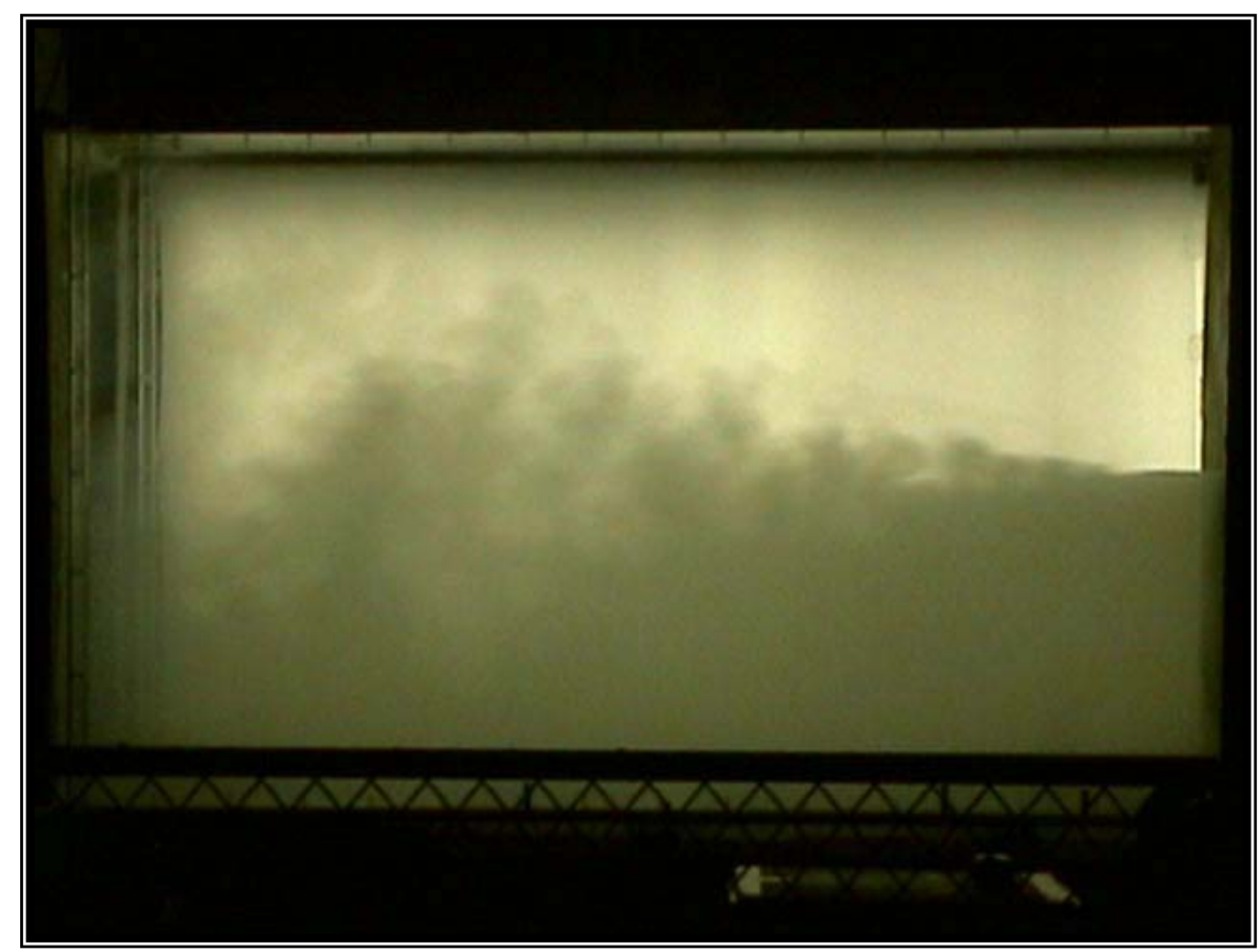

Figure 3. Gas channel at Atwood \# = 0.259 
Key task objectives that have been achieved over the life of the project have been detailed in previous scientific progress reports and in publications (listed in section 6). Here is a summary list of the main achievements of Task 1:

- Construction of a new RT statistically steady experiment for high Atwood (up to 0.75 ) studies of mixing processes in ICF.

- Obtaining a constant mass flow rate of helium from the supply bottles.

- Calibration and validation of the hot wire system for velocity measurements.

- Measurements for RT mixing up to an Atwood number of 0.21 , that include measurements of Reynolds stresses and density/velocity fluctuation crosscorrelations.

- Prevention of exit plenum back-flow.

- Running the facility up to Atwood numbers of 0.5 and collecting extensive datasets over a wide range of Atwood numbers (see publications listed in section 6 for details).

\subsection{Task 2: Collection of Initial Condition Data}

This task involves a new set of experimental measurements for initial conditions in our RT mixing experiments. These experimental initial conditions are then used to start corresponding DNS computer simulations of the RT mixing process (see the JFM paper referenced in section 6 under 6.1.7).

In the proposal this task was scheduled to begin in 2004, however, interest from LLNL and the availability of a graduate research assistant led us to start this task early using the water channel facility. This work has continued during 2004, as we continue our Alliances with LLNL and LANL, with data being transferred to Dr. Oleg Schilling at LLNL.

To illustrate the work Figure 4 below compares the experiment with DNS simulation, where computed temperature profiles and PLIF photographs are shown: (a) PLIF from the water channel at $x \approx 35 \mathrm{~cm}$; and, (b) 3D DNS (256 $\times 128 \times 256)$. The comparison is not quite one-to-one because the PLIF marker and temperature do not coincide perfectly (the temperature diffuses faster). 


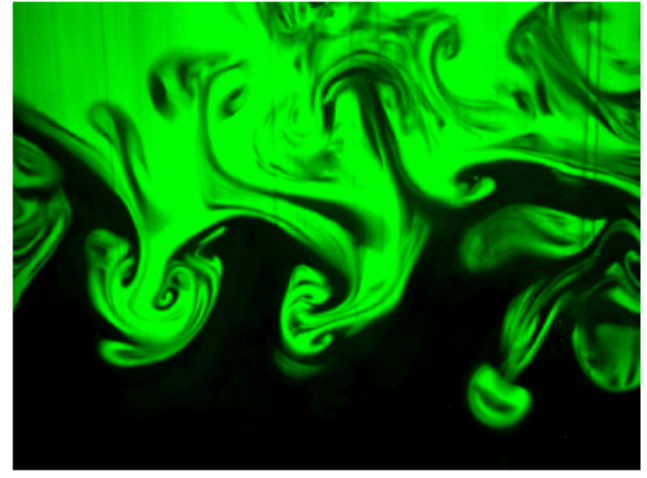

PLIF Image ${ }^{\dagger}$

$\tau \approx 1.2$

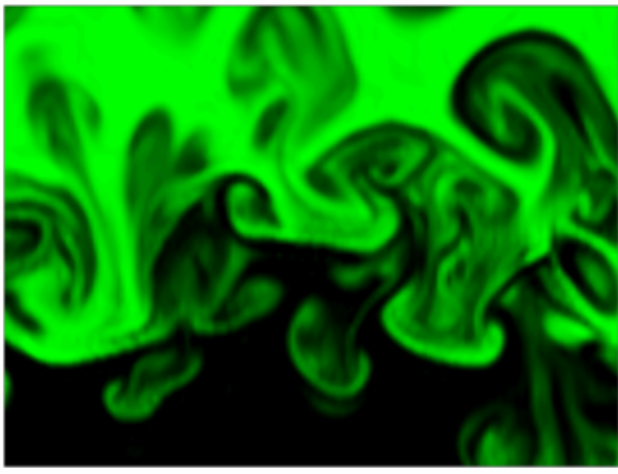

DNS

$\tau=1.21$

Figure 4. Comparison of experimental PLIF image with corresponding DNS simulation.

The summary of main achievements for this second task are:

- New measurements across the channel near the splitter plate.

- Extensive data collection near the splitter plate in the water channel - sufficient data to characterize the initial conditions.

- Successful comparison of experimentally measured developing RT mixing (including mix width, and high order statistical quantities such as density and velocity fluctuations), with DNS simulations based on the experimentally measured initial conditions.

- On-going work includes the resulting validated DNS is being used to compute terms in RANS models for model validation purposes.

\section{CURRENT AND FUTURE WORK}

The research is continuing with additional funding from the DOE and we are continuing to collect data at $\mathrm{At}=0.5$ and above, with the specific goal of collecting extensive statistical measurements of velocity and density fluctuations, and associated power spectra. These data in-turn will be provided to DOE collaborators that include colleagues at LANL and LLNL for RT model calibration and validation. 


\section{PARTICIPANTS AT TAMU DURING THE $3^{\text {rd }}$ YEAR}

PI:

Graduate Research Assistants:
Dr. Malcolm J. Andrews

Mr. Michael Martin (Ph.D.

Mr. Arindam Banerjee (Ph.D.)

Mr. Nicholas Mueschke (MSc./Ph.D.)

Mr. Wayne Kraft (MSc./Ph.D.)

Undergraduate Research Assistants: Ms. Amanda Dellaughter

Mr. Michael Peart

\section{ALLIANCE EXCHANGE ACTIVITIES}

- The PI has taken a Leave-of-Absence from Texas A\&M to join Los Alamos as a National Security Fellow.

- Dr. Praveen Ramaprabhu has started (12/8/2003) work at Los Alamos, and is continuing to perform RT research.

- Mr. Wayne Kraft and Mr. Nick Mueschke completed their PSc. Degrees and have joined the PhD research program of the PI to continue with their RT studies and obtain PhD's.

- Mr. Arindam Banerjee will complete his PhD in May 2006, and join the PI at LANL as a post-doc.

- The PI visited with LLNL and LANL collaborators throughout the year either at conferences or on the phone.

It is our pleasure to host Alliance collaborators to the water channel and gas channel facilities, and we are pleased to run the experiments, and involve colleagues in the research.

\section{PURCHASES}

There was no major single purchase this last year. However, we continued to purchase materials (e.g. helium, smoke fluid), miscellaneous diagnostic items (e.g. wire, connectors, probes), and continued with minor improvements to the facilities. 


\section{PUBLICATIONS AND PRESENTATIONS REFERENCING PROJECT (copies available upon request)}

\subsection{Journal Publications Since $2^{\text {nd }}$ Year Report}

6.1.1 Dimonte, G., Ramaprabhu, P., Youngs, D.L., Andrews, M.J., and Rosner, R., "Recent advances in the turbulent Rayleigh-Taylor instability," Physics of Plasmas, 12, May 2005.

6.1.2. Ramaprabhu, P., Dimonte, G., and Andrews, M.J., "About the Influence of Initial Perturbations on the Turbulent Rayleigh-Taylor Instability", Journal of Fluid Mechanics, July 26, 2005, p. 285-319.

6.1.3. Kraft, W., and Andrews, M.J., "Experimental Investigation of Unstably Stratified Buoyant Wakes,” ASME Journal of Fluids Engineering, to appear in May 2006.

6.1.4. Mueschke, N., and Andrews, M.J., "Investigation of Scalar Measurement Error in Diffusion and Mixing Processes,” Experiments in Fluids, Vol. 40, pp. 165-175, February, 2006.

6.1.5. Kraft, W., and Andrews, M.J., "Visualization of the Rayleigh-Taylor Instability," accepted to appear in the Journal of Flow Visualization, December, 2005.

6.1.6. Banerjee, A., and Andrews, M.J., "A Gas Channel Facility to Investigate Statistically Steady Rayleigh-Taylor Mixing at High Atwood Numbers,” accepted to Physics of Fluids, December, 2006.

6.1.7. Mueschke, N.J., Andrews, M.J., Schilling, O. “Experimental characterization of initial conditions and spatio-temporal evolution of a small Atwood number Rayleigh-Taylor mixing layer,” accepted to appear in Journal of Fluid Mechanics, April, 2006. LA-UR \# 05-7860.

\subsection{Conference Presentations Since $2^{\text {nd }}$ Year Report}

6.2.1 Banerjee, A., and Andrews, M.J., "Experimental Investigation of Statistically Steady Rayleigh-Taylor Mixing at High Atwood Numbers,” FEDSM2005-77154, 2005 ASME Fluids Engineering Summer Conference, Houston, Texas, USA, June 19-23, 2005.

6.2.2 Mueschke, N., Kraft, W.N., Dibua, O., Jacobs, J.W., and Andrews, M.J., "Numerical Investigation of Single-Mode Richtmyer-Meshkov Instability," FEDSM2005-77189, 2005 ASME Fluids Engineering Summer Conference, Houston, Texas, USA, June 19-23, 2005. 
6.2.3 Banerjee, A., and Andrews, M.J., "Density and Growth Rate Measurements in High Atwood Number Rayleigh-Taylor Mixing," Proceedings of IMECE2005, paper\#82725, ASME Mechanical Engineering Congress and Exposition, Orlando, Florida, November 5-11, 2005. LA-UR-05-8311.

6.2.4 Mueschke, N.J., Kraft, W.N., Jacobs, J.W., and Andrews, M.J., "Numerical Investigation of Internal Vortex Structure in Two-Dimensional, Incompressible, Richtmyer-Meshkov Flows,” Proceedings of IMECE2005, paper\#82723, ASME Mechanical Engineering Congress and Exposition, Orlando, Florida, November 5-11, 2005. LA-UR-05-8312.

6.2.5 Kraft, W.N., Banerjee, A., and Andrews, M.J., "Visualizations of Buoyancy Driven Mixing,” Proceedings of IMECE2005, paper\#82736, ASME Mechanical Engineering Congress and Exposition, Orlando, Florida, November 5-11, 2005. LA-UR-05-8313.

6.2.6 Kraft, W., Mueschke, N., Jacobs, J., and Andrews, M.J., "Numerical Investigation of Incompressible Richtmyer-Meshkov Instability," DFD2005, Bulletin of the American Physical Society, NQ.00006, Vol. 50, No. 9, p. 298, November, 2005.LA-UR-05-8793.

6.2.7 Banerjee, A., and Andrews, M.J., "Progress With the Velocity and Density Measurements in High Atwood Number Rayleigh-Taylor Mixing," DFD2005, Bulletin of the American Physical Society, NT.00003, Vol. 50, No. 9, p. 304, November, 2005. LA-UR-05-8792

6.2.8 Mueschke, N., Schilling, O., and Andrews, M.J, "Direct numerical simulation of a small Atwood number Rayleigh-Taylor instability-driven mixing layer," DFD2005, Bulletin of the American Physical Society, LT.00001, Vol. 50, No.9, p. 266, November, 2005. LA-UR-05-8794.

6.2.9 Schilling, O., Mueschke, N.J., and Andrews, M.J., "Direct Numerical Simulation of a Small Atwood Number Rayleigh-Taylor Instability-Driven Mixing Layer,” VIII Khariton Topical Scientific Readings, Sarov, Russia, March 21-24, 2006. LA-UR-06-1919.

\subsection{Other Presentations Since $2^{\text {nd }}$ Year Report}

6.3.1 Andrews, M.J., "Gas Channel Progress," presentation given to Complex Hydrodynamics Group, LLNL, January 27, 2005.

6.3.2 Andrews, M.J., “"Experimental Measurements of Turbulent Rayleigh-Taylor Mixing at Texas A\&M University: Recent Results, Outstanding Questions, and Future Work," given to Turb-Mix Group at LANL, April 4, 2005. 
6.3.3 Andrews, M.J., "Jason Briefing: An Overview of the Rational behind and Transfer of Experimental Data from Andrews Research Group at Texas A\&M University,” Mitre Corporation, July 1, 2005.

6.3.4 Andrews, M.J., "Plenary Lecture: Core Topic 3: Flow and Turbulence Part 2,” 1st International Conference on Advanced Computing and Simulation, DAMPT, Cambridge University, UK, July 4 to July 15, 2005. LA-UR-05-4908.

6.3.5 Andrews, M.J., "Opportunities for Direct Numerical Simulation of Rayleigh-Taylor Mix Experiments," Symposium on Modeling and Simulation of Variable Density and Compressible Turbulent Mixing, Los Alamos National Laboratory, August 3-5, 2005. LA-UR-05-5960.

6.3.6 Andrews, M.J., "Detailed Measurements of Turbulent Rayleigh-Taylor Mixing at Large and Small Atwood Numbers," Stewardship Science Academic Alliances (SSAA) Program Symposium August 23 - 25, 2005, Las Vegas, Nevada. LA-UR05-6211.

\subsection{Other Publications Since $2^{\text {nd }}$ Year Report}

6.4.1 Praveen Ramaprabhu (T-CNLS), Guy Dimonte (X-4), and M.J. Andrews (Texas A\&M University), “The Effect of Initial Conditions on the Rayleigh-Taylor Flow,” Research Highlights, Theoretical Division, Los Alamos National Laboratory, LA-UR-05, April, 2005.

6.4.2 Andrews, M.J., $2^{\text {nd }}$ year contractor report for DOE Stewardship Science Academic Alliances Program Sponsor ID \#: DE-FG03-02NA00060. Project Title: "Detailed Measurements of Rayleigh-Taylor Mixing at Large and Small Atwood Numbers,” December 14, 2004.

\section{FINANCIAL STATUS (as of April 2006)}

The project is now complete and all the money spent.

The \% time supported for this year is as follows:

\begin{tabular}{|l|l|c|}
\hline \multicolumn{1}{|c|}{ Position } & \multicolumn{1}{c|}{ Person } & Time \\
\hline PI & Dr. Malcolm J. Andrews & $0 \%$ \\
\hline Graduate Research Assistant & Mr. Wayne Kraft & $50 \%$ \\
\hline Graduate Research Assistant & Mr. Arindam Banerjee & $50 \%$ \\
\hline Graduate Research Assistant & Nicholas Mueschke & $50 \%$ \\
\hline Undergraduate Research Assistant & Ms. Amanda Dellaughter & $\sim 20 \%$ \\
\hline Undergraduate Research Assistant & Mr. Michael Peart & $\sim 20 \%$ \\
\hline
\end{tabular}




\section{APPENDIX A: Summary of Project Journal and Conference Publications}

\section{A.1 Journal Publications (9)}

A.1.1 Ramaprabhu, P., and Andrews, M.J., "Experimental Investigation of RayleighTaylor Mixing at Small Atwood Numbers," Journal of Fluid Mechanics, Vol. 502, pp. 233-271, March, 2004.

A.1.2 Ramaprabhu, P., and Andrews, M.J., "On the Initialization of Rayleigh-Taylor Simulations," Physics of Fluids A, Vol. 16, No. 8, pp. L59-L62, August 2004.

A.1.3 Dimonte, G., Ramaprabhu, P., Youngs, D.L., Andrews, M.J., and Rosner, R., "Recent advances in the turbulent Rayleigh-Taylor instability," Physics of Plasmas, 12, May 2005.

A.1.4 Ramaprabhu, P., Dimonte, G., and Andrews, M.J., "About the Influence of Initial Perturbations on the Turbulent Rayleigh-Taylor Instability", Journal of Fluid Mechanics, July 26, 2005, p. 285-319.

A.1.5 Kraft, W., and Andrews, M.J., "Experimental Investigation of Unstably Stratified Buoyant Wakes,” ASME Journal of Fluids Engineering, to appear in May 2006.

A.1.6 Mueschke, N., and Andrews, M.J., "Investigation of Scalar Measurement Error in Diffusion and Mixing Processes,” Experiments in Fluids, Vol. 40, pp. 165-175, February, 2006.

A.1.7 Kraft, W., and Andrews, M.J., "Visualization of the Rayleigh-Taylor Instability," accepted to appear in the Journal of Flow Visualization, December, 2005.

A.1.8 Banerjee, A., and Andrews, M.J., “A Gas Channel Facility to Investigate Statistically Steady Rayleigh-Taylor Mixing at High Atwood Numbers,” accepted to Physics of Fluids, December, 2006.

A.1.9 Mueschke, N.J., Andrews, M.J., Schilling, O. “Experimental characterization of initial conditions and spatio-temporal evolution of a small Atwood number Rayleigh-Taylor mixing layer," accepted to appear in Journal of Fluid Mechanics, April, 2006. LA-UR \# 05-7860.

\section{A.2 Conference Papers (24)}

A.2.1 Nicholas Mueschke (Texas A\&M University), Oleg Schilling (Lawrence Livermore National Laboratory), Malcolm Andrews (Texas A\&M University), 
"Investigation of Effects of Initial Conditions on Rayleigh-Taylor Mixing", DFD2003, Bulletin of the American Physical Society, November, 2003.

A.2.2 Nicholas Mueschke (Texas A\&M University), Oleg Schilling (Lawrence Livermore National Laboratory), ,"Direct Numerical Simulation of Experiments on Rayleigh-Taylor Instability Induced Rayleigh-Taylor Mixing", DFD2003, Bulletin of the American Physical Society, November, 2003.

A.2.3 Praveen Ramaprabhu (Texas A\&M University), Guy Dimonte (Los Alamos National Laboratory), Malcolm Andrews (Texas A\&M University), "Influence of initial conditions on the growth of the turbulent Rayleigh-Taylor mix", DFD2003, Bulletin of the American Physical Society, November, 2003.

A.2.4 Praveen Ramaprabhu, Malcolm Andrews (Texas A\&M University), "On Experimental Measurements as Initial Conditions for Simulations of RayleighTaylor Mixing," DFD2003, Bulletin of the American Physical Society, November, 2003.

A.2.5 Wayne Kraft, Malcolm Andrews (Texas A\&M University), "An Experimental Investigation of Non-Equilibrium Rayleigh-Taylor Mixing," DFD2003, Bulletin of the American Physical Society, November, 2003.

A.2.6 Mueschke, N., Schilling, O., and Andrews, M.J., "Measurement of Initial Conditions of a ayleigh-Taylor Mixing Layer" DFD2004, Bulletin of the American Physical Society, Vol. 49, No.9, p. 223, November, 2004.

A.2.7 Mueschke, N., Schilling, O., and Andrews, M.J., "Direct Numerical Simulations of Rayleigh-Taylor Mixiing with Experimentally Measured Initial Conditions" DFD2004, Bulletin of the American Physical Society, Vol. 49, No.9, p. 223, November, 2004.

A.2.8 Kraft, N.W., and Andrews, M.J., "A Stratified Buoyant Wake” DFD2004, Bulletin of the American Physical Society, Vol. 49, No.9, p. 224, November, 2004.

A.2.9 Banerjee, A., and Andrews, M.J., "Progress with a High Atwood Number Statistically Steady Rayleigh-Taylor Mix Experiment” DFD2004, Bulletin of the American Physical Society, Vol. 49, No.9, p. 222, November, 2004.

A.2.10 Kraft, N.W., and Andrews, M.J., "Experimental Investigation of Stratified, Buoyant Wakes” Paper \# HT-FED2004-56623, 2004 ASME Heat Transfer/Fluids Engineering Summer Conference Westin Charlotte \& Convention Center Charlotte, North Carolina, USA July 11-15, 2004, Proceedings: ISBN: 0-7918$3740-8$. 
A.2.11 Mueschke, N., and Andrews, M.J., "Investigation of Scalar Measurement Error in Diffusion and Mixing Processes” Paper IMECE2004-60993, 2004 ASME International Mechanical Engineering Congress \& Exposition, Anaheim, California, USA, Nov. 13-19, 2004, Proceedings: ISBN: 0-7918-4178-2.

A.2.12 Kraft, W.N., and Andrews, M.J., "Visualization of Rayleigh-Taylor Instability," poster, $9^{\text {th }}$ International Workshop on the Physics of Compressible Turbulent Mixing, Cambridge, UK, 19-23, July, 2004.

A.2.13 Ramaprabhu, P., and Andrews, M.J., "An Overview of Rayleigh-Taylor experiments at Texas A\&M University," poster, $9^{\text {th }}$ International Workshop on the Physics of Compressible Turbulent Mixing, Cambridge, UK, 19-23, July, 2004.

A.2.14 Dimonte, G., Ramaprabhu, P., and Andrews, M.J., "Dependence of Self-Similar Rayleigh-Taylor Growth on Initial Conditions," presentation, $9^{\text {th }}$ International Workshop on the Physics of Compressible Turbulent Mixing, Cambridge, UK, 19-23, July, 2004.

A.2.15 Schilling, O., Mueschke, N., and Andrews, M.J., "Direct Numerical Simulations of Miscible, Small Atwood Number Rayleigh-Taylor Instability-Induced Mixing," presentation, $9^{\text {th }}$ International Workshop on the Physics of Compressible Turbulent Mixing, Cambridge, UK, 19-23, July, 2004.

A.2.16 Banerjee, A., and Andrews, M.J., "Experimental Investigation of Statistically Steady Rayleigh-Taylor Mixing at High Atwood Numbers," FEDSM2005-77154, 2005 ASME Fluids Engineering Summer Conference, Houston, Texas, USA, June 19-23, 2005.

A.2.17 Mueschke, N., Kraft, W.N., Dibua, O., Jacobs, J.W., and Andrews, M.J., "Numerical Investigation of Single-Mode Richtmyer-Meshkov Instability," FEDSM2005-77189, 2005 ASME Fluids Engineering Summer Conference, Houston, Texas, USA, June 19-23, 2005.

A.2.18 Banerjee, A., and Andrews, M.J., "Density and Growth Rate Measurements in High Atwood Number Rayleigh-Taylor Mixing,” Proceedings of IMECE2005, paper\#82725, ASME Mechanical Engineering Congress and Exposition, Orlando, Florida, November 5-11, 2005. LA-UR-05-8311.

A.2.19 Mueschke, N.J., Kraft, W.N., Jacobs, J.W., and Andrews, M.J., "Numerical Investigation of Internal Vortex Structure in Two-Dimensional, Incompressible, Richtmyer-Meshkov Flows,” Proceedings of IMECE2005, paper\#82723, ASME Mechanical Engineering Congress and Exposition, Orlando, Florida, November 5-11, 2005. LA-UR-05-8312.

A.2.20 Kraft, W.N., Banerjee, A., and Andrews, M.J., "Visualizations of Buoyancy Driven Mixing,” Proceedings of IMECE2005, paper\#82736, ASME Mechanical 
Engineering Congress and Exposition, Orlando, Florida, November 5-11, 2005. LA-UR-05-8313.

A.2.21 Kraft, W., Mueschke, N., Jacobs, J., and Andrews, M.J., "Numerical Investigation of Incompressible Richtmyer-Meshkov Instability,” DFD2005, Bulletin of the American Physical Society, NQ.00006, Vol. 50, No. 9, p. 298, November, 2005.LA-UR-05-8793.

A.2.22 Banerjee, A., and Andrews, M.J., "Progress With the Velocity and Density Measurements in High Atwood Number Rayleigh-Taylor Mixing," DFD2005, Bulletin of the American Physical Society, NT.00003, Vol. 50, No. 9, p. 304, November, 2005. LA-UR-05-8792

A.2.23 Mueschke, N., Schilling, O., and Andrews, M.J, "Direct numerical simulation of a small Atwood number Rayleigh-Taylor instability-driven mixing layer," DFD2005, Bulletin of the American Physical Society, LT.00001, Vol. 50, No.9, p. 266, November, 2005. LA-UR-05-8794.

A.2.24 Schilling, O., Mueschke, N.J., and Andrews, M.J., "Direct Numerical Simulation of a Small Atwood Number Rayleigh-Taylor Instability-Driven Mixing Layer," VIII Khariton Topical Scientific Readings, Sarov, Russia, March 21-24, 2006. LA-UR-06-1919. 